\section{International vernetzt über Allergien nachdenken}

\author{
Beim ersten Global Allergy Forum im Juli 2011 in Davos diskutierten \\ mehr als 40 weltweit renommierte Wissenschaftler über Probleme \\ und Lösungsansätze der Allergologie. Die Ergebnisse der von CK-CARE \\ initiierten Konferenz werden in einer „Davoser Erklärung“ zusammen- \\ gefasst. Sie soll neue Akzente im Nachdenken über Allergien setzen.
}

V or nur zwei Jahren gründete die Schweizer Kühne-Stiftung mit dem Christine Kühne - Center of Allergy Research and Education (CK-CARE) ein internationales Zentrum, das sich der Forschung und Wissensvermittlung auf dem Gebiet der Allergien widmet. Unter dem Motto „allergy barriers to cure“ lud CK-CARE zum ersten Global Allergy Forum (GAF) vom 17. bis 20. Juli 2011 in Davos. Dort diskutierten über 40 Wissenschaftler aus der Allergologie und damit verwandten Forschungsdisziplinen - unter ihnen die Nobelpreisträger Prof. Dr. Andrew Fire und Prof. Dr. Harald zur Hausen - Probleme, Lösungsansätze und Aktionspläne.

Die Forumsteilnehmer waren sich einig, dass auf dem hochkomplexen Gebiet der Allergien eine noch bessere und internationale Vernetzung von Forschenden aus verschiedenen Wissenschaftsfeldern in die Wege geleitet werden muss. Zugleich konstatierten sie, dass vorhandenes Wissen nicht genügend in den Alltag praktizierender Ärzte und

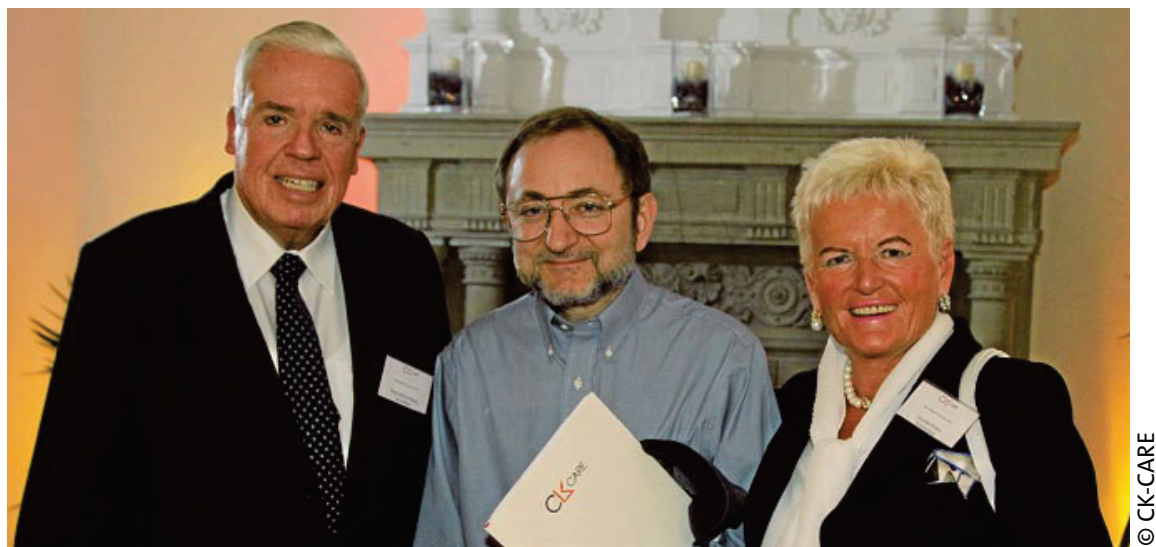

Sie machten das Global Allergy Forum erst möglich: Stifter-Ehepaar Christine und Prof. Dr. Klaus-Michael Kühne, hier mit Nobelpreisträger Prof. Dr. Andrew Fire (Mitte).
Fit in Schule und Job

Im frühen Kindesalter auftretende

Ekzeme können sich nicht nur während der Krankheitsphase, sondern auch noch Jahre später in der Schulzeit auf das Seelenleben auswirken. Eine Rolle spielen dabei Schlafmangel, Konzentrationsprobleme und Minderwertigkeitsgefühle aufgrund der juckenden Ekzeme. Daher ist es wichtig, dafür zu sorgen, dass es gar nicht oder seltener zu Schüben kommt. Wie das mit der richtigen Hautpflege und einer proaktiven Therapie gelingt, erklärt die Patientenbroschüre „Krankheitsbild und neue Behandlungsstrategien der Neurodermitis" der Deutschen Haut- und Allergiehilfe. Eine weitere Broschüre mit dem Titel „Chronisches Handekzem" klärt Patienten mit beruflich bedingten Hautkrankheiten über die Vorteile und den Ablauf des Hautarztverfahrens auf. Beide Broschüren können kostenlos über das Internet unter www.dha-neurodermitis.de angefordert werden. die Idee der Konferenz, die er als Mitglied des Direktoriums von CK-CARE initiiert hat: „Ähnlich wie der Club of Rome vor Jahrzehnten neue Akzente in unserem Denken über die Umwelt gesetzt hat, könnte das Global Allergy Forum Davos solches im Bereich der Allergien tun". Nobelpreisträger Andrew Fire bewertete das Global Allergy Forum als eine ,großartige Plattform, wo sich Experten aus verschiedenen Disziplinen austauschen und voneinander lernen".

red

\section{Versteckte Immundefekte}

Selbst hinter häufigen Hauterkrankungen kann ein seltener primärer Immundefekt (ID) stehen. Diese Möglichkeit wird jedoch nicht immer in den differenzialdiagnostischen Prozess einbezogen. Daher wird ein primärer Immundefekt oft erst zu einem Zeitpunkt erkannt, zu dem sich schon irreversible Organschädigungen entwickelt haben können. Um die Diagnostik zu verbessern, hat die Initiative FIND-ID eine Broschüre für Dermatologen veröffentlicht, die über Früherkennungsmerkmale und Therapiemöglichkeiten primärer Immundefekte bei Kindern und Erwachsenen aufklärt. Die Broschüre ist in abgewandelter Form auch für HNO-Ärzte und Pneumologen erhältlich. Alle Broschüren können unter www.find-id.net/download.html kostenlos im Internet heruntergeladen werden. FIND-ID ist ein Netzwerk von Zentren, Ärzten und Patientenorganisationen, die sich mit primären Immundefekten befassen.

red 